\title{
Altered Sleep Duration and Poor Quality of Sleep Among Pharmacy Students Amidst COVID-19 Lockdown: A South-Indian Study
}

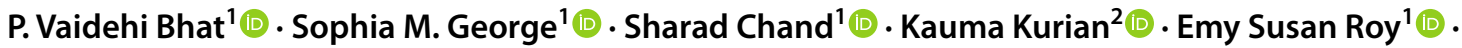

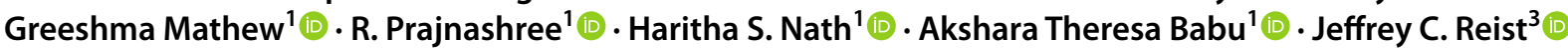

Received: 13 September 2021 / Revised: 1 October 2021 / Accepted: 14 October 2021 / Published online: 29 October 2021

(C) The Author(s), under exclusive licence to Springer Nature Singapore Pte Ltd. 2021

\begin{abstract}
Introduction/background The nationwide lockdown enforced due to the spread of coronavirus disease-2019 had a definite impact on sleep.

Objective To observe any changes in the duration, pattern and quality of sleep among pharmacy students due to the lockdown. Methods A google form-based cross-sectional and descriptive study was carried out after approval was obtained from the ethical committee in the month of July 2021 among 310 pharmacy students. The validated form was electronically administered after obtaining the informed consent. All the data pertaining to duration, pattern and quality of sleep before and during the lockdown was collected and analyzed using STATA version 16.0.

Results and Discussion Out of 310 participants, the study revealed an increase in the time needed to fall asleep ( $p$ value $<0.001)$ and in the total duration of sleep ( $p$ value $<0.001)$. A delay in the time of sleep in the morning ( $p$ value $<0.001)$ and at night $(p$ value $<0.001)$ was also one among the many significant results. The incidences of jerky leg movements $(p$ value $<0.001)$, snoring $(p$ value $<0.001)$, frequent nightmares $(p$ value $<0.001)$ and anxiety $(p$ value $<0.001)$ were also increased as a direct effect of the lockdown.

Conclusion The study has confirmed the detrimental impact of the lockdown on sleep among pharmacy students. All attributes of sleep duration and sleep quality have achieved statistical significance signifying the need to develop cognitive behavioral interventions and prevent the worsening of mental health amidst the COVID-19 era.
\end{abstract}

Keywords COVID-19 $\cdot$ Lockdown $\cdot$ Mental health $\cdot$ Pharmacy $\cdot$ Sleep

Sophia M. George

sophiamgeorge.108@gmail.com

P. Vaidehi Bhat

bhatpvaidehi@gmail.com

Sharad Chand

sureechand193@gmail.com

Kauma Kurian

kurian.kauma@gmail.com

Emy Susan Roy

emysusanroy@yahoo.com

Greeshma Mathew

greeshmamathew1998@gmail.com

R. Prajnashree

prajnashree234@gmail.com
Haritha S. Nath

harithasnath123@gmail.com

Akshara Theresa Babu

aksharatheresababu96@gmail.com

Jeffrey C. Reist

jeffrey-reist@uiowa.edu

1 Department of Pharmacy Practice, NGSM Institute of Pharmaceutical Sciences (NGSMIPS), Nitte (Deemed To Be University), Mangalore, India

2 MAMTA Health Institute for Mother and Child, New Delhi, India

3 College of Pharmacy, University of Iowa, 180S. Grand Avenue 169 CPB, Iowa City, IA 52242, USA 


\section{Introduction}

The first case of Coronavirus disease-2019 (COVID-19) virus was confirmed in December 2019 and it eventually went on to cause a global health crisis within a small-time frame [1]. This deadly virus quickly crossed international borders and caused several countries to impose an emergency lockdown and restrict social gatherings of any kind to contain the spread of the virus [2]. The government of India forced a nationwide lockdown during the first wave of the pandemic from 24th March 2020 to 31st May 2020 which was gradually lifted in a phased manner [3]. The global population was influenced by the pandemic in diverse ways. The economy of every nation was severely affected which consequentially, led to millions of people losing their jobs. The student population in India had to undergo a complete transformation in the landscape of teaching and learning into an entirely virtual reality with an attempt to continue the educational process [4].

Studies assessing the impact of the lockdown on academia and the teaching-learning process were carried out and results have revealed that the sudden shift from classroom teaching to the virtual mode was initially difficult to adapt to. The students were compelled to spent long hours in front of digital gadgets such as mobiles and laptops [5]. Various studies reported the impact of the nationwide lockdown on the mental health and sleep behavior of frontline health workers in addition to the general population [4]. Some additional studies were evidenced in the literature and these highlighted the impact of the lockdown on the mental dimension of health in many vulnerable subsets of population [2]. Although there are studies revealing the higher incidences of anxiety, depression and suicidal thoughts as an impact of lockdown among various subgroups of population, there is still a paucity of information of these effects on the sleep architecture of students during the lockdown [4].

The further consequences of the lockdown that have affected student experiences include graduation delays, job losses, job offer acceptance reductions, internship interruptions, separation from family, travel bans, and isolation and these have all significantly impacted their sleep hygiene and health. The severe restriction of physical activity, altered eating habits and the extensive use of internet and electronic gadgets have furthered worsened the risk for the development of sleep disorders among this subgroup [6]. These lifestyle changes have worsened the mental health and has significantly affected sleep quality and duration among the student population. Thus, in this study, due to the existing gap in knowledge, we have attempted to evaluate the impact of the partial and complete lockdown on the sleep architecture of college going pharmacy students in the southern coastal state of Karnataka, India.

\section{Materials and Methods}

\subsection{Study Design, Duration and Sample Size}

A Google form-based cross-sectional study was carried out in the month of July, 2021 among 310 pharmacy students.

\subsection{Study Subjects and Inclusion Criteria}

Students pursuing pharmacy courses in the state of Karnataka, aged between 17 and 30 years were included in the study after obtaining their willingness to participate in the online survey, whereas students who did not grant their consent and who had any previous diagnosis of psychiatric or sleep disorders were excluded.

\subsection{Ethical Approval}

The proposed study was initiated only after institutional ethical approval was secured.

\subsection{Study Procedure}

\subsubsection{Development and Validation of the Data Collection Form (Google-survey Form)}

The initial draft copy of the Google survey form was prepared by referring various primary, secondary and tertiary sources of information. The required validation assessment criteria were formulated based on content, relevance, clarity, readability and ambiguity of the form. To carry out the content validation, the prepared form was sent to a panel of subject experts that included a physician, a clinical pharmacist, an academic pharmacist and a nursing personnel. The form was assessed by the expert committee and suitable modifications were made after incorporating the recommended suggestions. The corrected form was resent to the committee and validated. The final version of the validated form consisted of statements of volunteer's willingness to participate in the study followed by their demographic details. The second section included four questions on the duration and pattern of sleep, while the third section had five questions that assessed the quality of the student's sleep. The responses for each of these questions both before and during the lockdown was planned to be obtained. The final version of the form was then disseminated among the students via electronic mail to collect all the relevant information for the study.

\subsubsection{Data Collection}

The data were collected using the convenient sampling method. The single response link of the data collection form 
accompanied by the objectives of the study were sent to the students. The volunteer informed consent was obtained from the participants after all the necessary information on the study procedure was given and after they clicked the "Yes, I consent" tab at the top of data collection form. The grant of consent by the participant would direct them to the main questionnaire. The student's identity was kept confidential during and after the study. The electronic responses of the students were checked for possible errors; the complete and relevant responses were downloaded in a Microsoft Excel file and transferred to the STATA software version 16.0 for further analysis of the obtained data.

\subsection{Data Analysis}

The qualitative data were analyzed using descriptive statistics in terms of frequency and percentage. Socio-demographic details and quantitative data were calculated in terms of mean \pm standard deviation. The significant changes in the pattern, duration and quality of sleep were analyzed after cross-tabulation. The Pearson Chi-square test and Fisher's exact test using the Software for Statistics and Data Science (STATA Version 16.0) software was calculated for the selected variables. A $p$ value of $<0.05$ was considered as statistically significant.

\section{Results}

\subsection{Distribution of Study Participants Based on Their Socio-demographic Details}

A total of 310 participants who satisfied the inclusion criteria were enrolled after their consent and completion of the survey questionnaire. The 238 (76.77\%) female participants outnumbered the males $72(23.23 \%)$ by a vast majority. The age of the participants ranged between 18 and 25 years with a mean age of $20.26 \pm 1.25$ SD years with the mean age of males and females being almost similar. A majority of the participants were 21 years $(94,30.32 \%)$, followed by
$20(76,24.51 \%)$ and 19 years $(61,19.67 \%)$, whereas the least belonged to the age group of 25 years $(1,0.3 \%)$. The statistical analysis revealed no significant association of age with changes in the pattern, duration and quality of sleep. The socio-demographic details have been clearly depicted in Table 1.

\subsection{Details on the Sleep Duration and Pattern Before and During Lockdown}

The detailed analysis on the sleep duration and pattern before and during lockdown was performed which was followed by a subgroup analysis based on gender. The findings on sleep duration and pattern before lockdown revealed that most of the students $(242,78.06 \%)$ slept for $6-8 \mathrm{~h}$ and the sleep latency for 140 students $(45.16 \%$ ) was around $10-30 \mathrm{~min}$. However, the number of participants sleeping adequately for $6-8 \mathrm{~h}$ was reduced to $180(58.06 \%)$ and the number of participants who took more than $30 \mathrm{~min}$ to fall sleep was doubled during the lockdown. It was also noted that during the lockdown, the number of students who slept for more than $8 \mathrm{~h}$ increased drastically from 16 to 109 . The student's time of waking up (after $10 \mathrm{am}$ ) and going to sleep (after $12 \mathrm{pm}$ ) were noted to be more than doubled as a direct consequence of the lockdown. In the subgroup analysis based on gender, maximum $61(84.72 \%)$ males slept for 6-8 $\mathrm{h}$ and these figures significantly reduced to 47 (65.28\%) during the lockdown. Apart from the total sleep duration among females and the total population, all other variable achieved statistical significance before and during the lockdown and these details accompanied by their $\mathrm{p}$ values are detailed in Table 2.

\subsection{Details on the Sleep Quality Before and During the Lockdown}

The quality of sleep followed by a subgroup analysis of all the study participants was performed and analyzed in detail. The analysis revealed highly significant differences across all parameters that are relevant to sleep quality among the
Table 1 Distribution of study participants based on their socio-demographic details

\begin{tabular}{llllll}
\hline Socio-demographic details & Age (years) & Males, $n(\%)$ & Females, $n(\%)$ & Total, $n(\%)$ & $P$-value \\
\hline Age-wise distribution & 18 & $8(11.11)$ & $21(8.82)$ & $29(9.35)$ & 0.201 \\
& 19 & $16(22.22)$ & $45(18.91)$ & $61(19.68)$ & \\
& 20 & $13(18.06)$ & $63(26.47)$ & $76(24.52)$ & \\
& 21 & $18(25.00)$ & $76(31.93)$ & $94(30.32)$ & \\
& 22 & $17(23.61)$ & $30(12.61)$ & $47(15.16)$ & \\
& 23 & - & $2(0.84)$ & $2(0.65)$ & \\
Mean age & 25 & - & $1(0.42)$ & $1(0.32)$ & \\
& - & $72(100)$ & $238(100)$ & $310(100)$ & \\
\hline
\end{tabular}




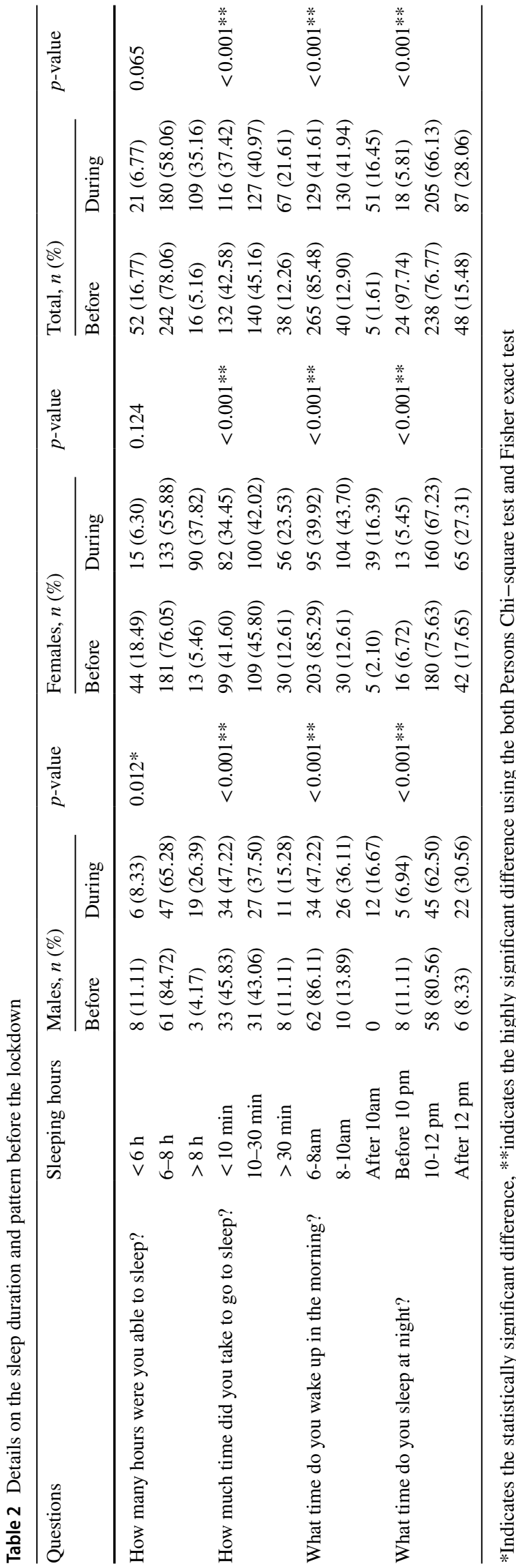

study participants before and during the lockdown period. The gender-based subgroup analysis clearly revealed that the quality of sleep among males and females was notably affected as a consequence of the lockdown. The details pertaining to the sleep architecture of all pharmacy students before and during the lockdown is referenced in Table 3.

\section{Discussion}

This study was carried out to look out for any variations in the duration, pattern and quality of sleep among pharmacy students before and during the lockdown. The study enrolled 310 participants, aged between 18 and 25 years with a mean age of around 20 years. The number of female students enrolled in pharmacy courses was more than three times that of males, which was similar to the study carried out by Romero-Blanco et al., among nursing students [7]. It also reveals an existent gender disparity wherein more women tend to take up and practice pharmacy in comparison to their male counterparts ( $83.9 \%$ versus $65.2 \%$ ), respectively, according to a report released on April 8th, 2014 by the National Pharmacist Workforce Survey [8].

The statistical analysis to see the association of age with sleep parameters displayed no significant finding which might possibly be because all participants predominantly belong to the age group of 18-25 years. The analysis on the duration and sleep pattern of the study participants revealed significant changes in the duration of sleep among males, which was insignificant among females and in the total population. This can be attributed to the general tendency of males to sleep longer without affecting their sleep quality [9]. Study parameters like the time taken to fall asleep, time of sleep and waking up were significantly changed in all the participants and these changes were consistent on a gender-based subgroup analysis as well. This, implies that, irrespective of gender, the duration and pattern of sleep for all of them were severely impaired during the lockdown. This can be attributed to the nationwide lockdown resulting in complete restriction of movement and a temporary substitution of classroom teaching to the virtual platform. The duration and parameter-based findings revealed the shift in bedtime and waking time in majority of the participants, which was similar to the findings published by Kaditis et al., that noted a similar change in the sleep and wake time of the participants [10]. The sudden shift of in-house learning to the virtual mode caused students to spend a lot of time in front of electronic gadgets which indefinitely tends to affect sleep health and hygiene. In addition to the daily routine of students being affected, the national lockdown has also affected the level of daily physical activity and the eating habits of students [11] which has a potential impact on sleep hygiene as well. 


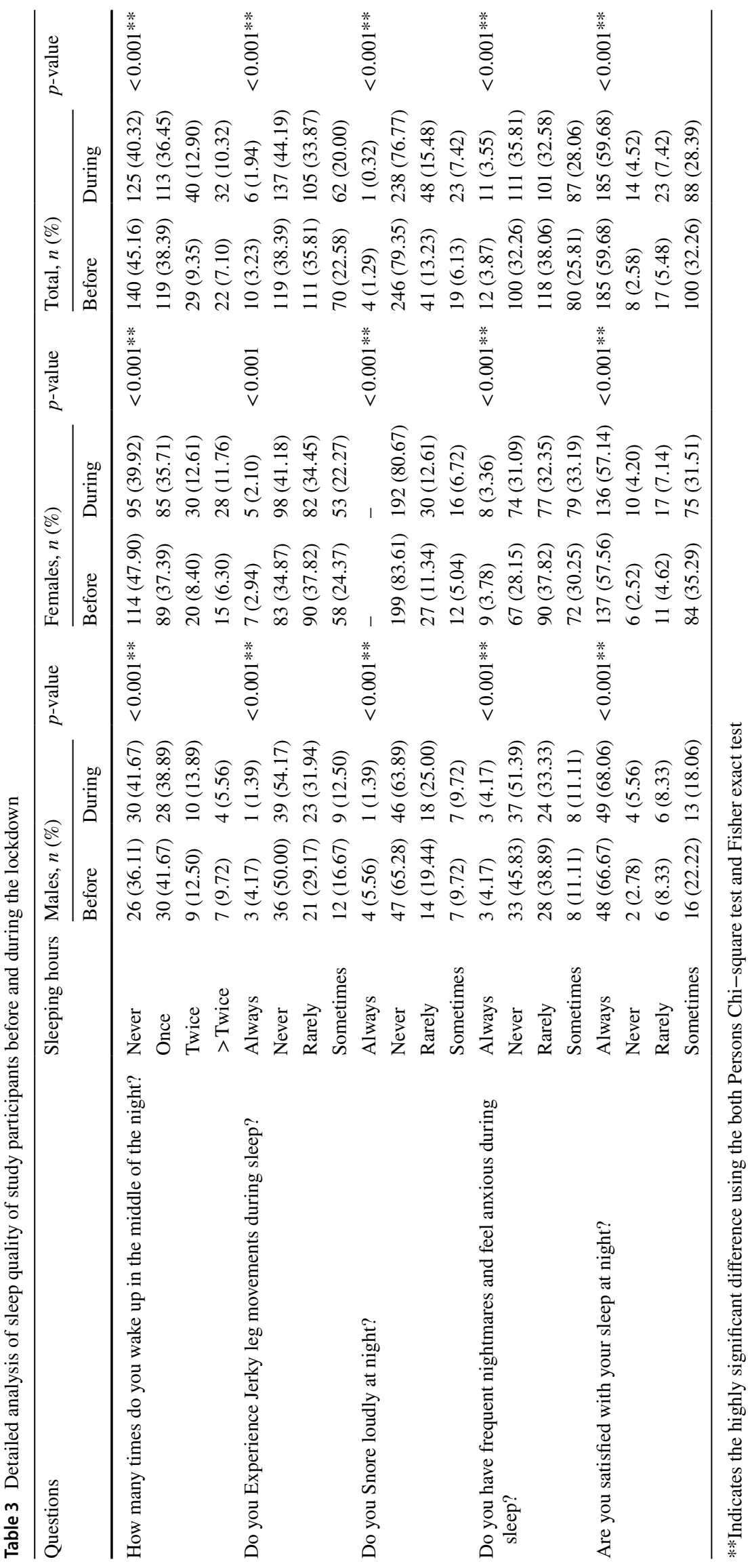


A newsletter published in John Hopkin's on April 2020, covered details on "How online learning can affect the student health", wherein, the newsletter critically discussed the possible adverse effects and consequences of prolonged exposure and usage of media on the mental and sleep health of students [12].

An article published in "The Economic Times" revealed the increased consumption of data in India during the lockdown period as reported by the telecom authority of India and an article in Business Today India reported an $87 \%$ surge of social media usage during the pandemic with the predominant users being the young adult population [13, 14]. All these factors could have contributed to changes in the sleep pattern and duration. The excessive leisure time available at hand due to the closure of universities in addition to the inability to even step out of one's home could be potential reasons for long hours of sleep.

Sleep quality of the patients before and during the lockdown also revealed highly significant changes. The increase in the duration of sleep during day light hours due to the increased time at hand for leisure might be the reason for the unusual awakening and frequent disturbances in sleep. The increased incidences of jerky limb movements at night could be attributed to the alterations in the mood, stress, fear and anxiety levels during the 2 nd wave of the disease [15]. Similarly, a statistically significant incidence in snoring could be because of the long hours of poor posture maintained by the students as they were forced to spend more than half their day either in front of their phones or laptops for classes or recreational purposes. The lockdown also caused many college going students to while away a substantial amount of time by simply lying in bed with very limited movement and exercise [16] which could have also raised the incidence of snoring at night. The widespread fear of contracting COVID19 , sudden shift of learning and lifestyle, loss of jobs within the family and uncertainty about the future of one's own and family's financial status could be major contributing reasons for the abrupt increase in nightmares and anxiety during the lockdown. These results on poor sleep quality were in accordance with the study conducted by Alfonsi et al., where dissociative and poor quality of sleep were reported $[17,18]$. However, a detailed study on the association of various factors with the disturbed duration, pattern and quality of sleep was not conducted which the authors mention to be the main limitation of this study.

\section{Conclusion}

On the basis of a thorough review of literature, it can be hypothesized that the sleep hygiene of university going students would have been significantly affected during the global pandemic. This study focuses on recognizing and stratifying these sleep health issues. Aspects of sleep duration such as the time of awakening and sleeping including sleep latency observed highly significant results. Similarly, all facets of sleep quality such as jerky leg movements, snoring, nightmares, anxiety and the number of times of awakening were notably affected during the lockdown. The study highlights the need to focus on the mental health of this population during the COVID-19 era and broadens the scope for more research in this field.

Acknowledgements We authors wants to thank NGSMIPS for their support during the conduct of research study.

Funding Nil.

\section{Declarations}

Conflict of interest Authors declare no conflict of interest.

\section{References}

1. Chauhan S. Comprehensive review of coronavirus disease 2019 (COVID-19). Biomed J. 2020;43(4):334-40. https://doi.org/10. 1016/j.bj.2020.05.023.

2. Nepal S, Nepal S, Shastry CS, Chand S, Nandakumar UP, Pant $\mathrm{BD}$, et al. Impact of COVID-19 on mental dimension of health: a sensitive issue to be addressed at the earliest. Curr Psychiatry Res Rev. 2020;16(03):158-66. https://doi.org/10.5530/jyp.2021. 13.21.

3. Pal R, Yadav U, Grover S, Saboo B, Verma A, Bhadada SK Knowledge, attitudes and practices towards COVID-19 among young adults with type 1 diabetes mellitus amid the nationwide lockdown in India: a cross-sectional survey. Diabetes Res Clin Pract. 2020;166: 108344. https://doi.org/10.1016/j.diabres.2020. 108344.

4. Sinha M, Pande B, Sinha R. Impact of COVID-19 lockdown on sleep-wake schedule and associated lifestyle related behavior: a national survey. J Public Health Res. 2020;9(3):1826. https://doi. org/10.4081/jphr.2020.1826.

5. Camargo CP, Tempski PZ, Busnardo FF, Martins MA, Gemperli R. Online learning and COVID-19: a meta-synthesis analysis. Clinics (Sao Paulo). 2020;75: e2286. https://doi.org/10.6061/clini cs/2020/e2286.

6. Marelli S, Castelnuovo A, Somma A, Castronovo V, Mombelli S, Bottoni D, et al. Impact of COVID-19 lockdown on sleep quality in university students and administration staff. J Neurol. 2021;268(1):8-15. https://doi.org/10.1007/s00415-020-10056-6.

7. Romero-Blanco C, Rodríguez-Almagro J, Onieva-Zafra MD, Parra-Fernández ML, Prado-Laguna MDC, Hernández-Martínez A. Sleep pattern changes in nursing students during the COVID19 lockdown. Int J Environ Res Public Health. 2020;17(14):5222. https://doi.org/10.3390/ijerph17145222.

8. Woman gain ground in pharmacy profession. Drug topics. 2015. Available at: https://www.drugtopics.com/view/women-gainground-pharmacy-profession. Accessed 2 Aug 2021

9. Krishnan V, Collop NA. Gender differences in sleep disorders. Curr Opin Pulm Med. 2006;12(6):383-9. https://doi.org/10.1097/ 01.mcp.0000245705.69440.6a.

10. Kaditis AG, Ohler A, Gileles-Hillel A, Choshen-Hillel S, Gozal D, Bruni O, et al. Effects of the COVID-19 lockdown on sleep 
duration in children and adolescents: a survey across different continents. Pediatr Pulmonol. 2021;56(7):2265-73. https://doi. org/10.1002/ppul.25367.

11. Diet and exercise and sleep. Sleep Foundation. 2020. Available at: https://www.sleepfoundation.org/physical-health/diet-exercisesleep. Accessed 2 Aug 2021

12. How online learning can affect the student health. The John Hopkin's newsletter. 2020. Available from: https://www.jhunewslet ter.com/article/2020/04/how-online-learning-can-affect-studenthealth. Accessed 1 Aug 2021

13. Lockdown leads to a $30 \%$ spike in data consumption. The Economic Times. 2020. Available from: https://telecom.economicti mes.indiatimes.com/news/lockdown-leads-to-a-30-spike-in-dataconsumption-ey/76387834. Accessed 1 Aug 2021

14. Coronavirus: $87 \%$ increase in social media usage amid lockdown. Business Today India. 2021. Available from: https://www.busin esstoday.in/technology/news/story/coronavirus-87-percent-incre ase-in-social-media-usage-amid-lockdown-indians-spend-4hours-on-facebook-whatsapp-253431-2020-03-30. Accessed 1 Aug 2021

15. Khare R, Mahour J, Ohary R, Kumar S. Impact of online classes, screen time, naps on sleep, and assessment of sleep-related problems in medical college students during lockdown due to coronavirus disease-19 pandemic. Natl J Physiol Pharm Pharmacol. 2021;11(01):56-61. https://doi.org/10.5455/njppp.2021.10. 09235202006092020.

16. Snoring more could be a result of lockdown, expert claims. WalesOnline UK. 2020. Available from: https://www.walesonline.co. uk/news/uk-news/snoring-more-could-result-lockdown-18395402. Accessed 1 Aug 2021

17. Kilius E, Abbas NH, McKinnon L, Samson DR. Pandemic nightmares: COVID-19 lockdown associated with increased aggression in female university students' dreams. Front Psychol. 2021;12: 644636. https://doi.org/10.3389/fpsyg.2021.644636.

18. Scarpelli S, Alfonsi V, Mangiaruga A, Musetti A, Quattropani MC, Lenzo V, et al. Pandemic nightmares: effects on dream activity of the COVID-19 lockdown in Italy. J Sleep Res. 2021. https:// doi.org/10.1111/jsr.13300.

Publisher's Note Springer Nature remains neutral with regard to jurisdictional claims in published maps and institutional affiliations. 